\title{
Design, Synthesis and Study of Antibacterial and Antitubercular Activity of Quinoline Hydrazone Hybrids
}

https://doi.org/10.1515/hc-2020-0109

Received May 21, 2020; accepted August 08, 2020.

\begin{abstract}
Emerging bacterial resistance is causing widespread problems for the treatment of various infections. Therefore, the search for antimicrobials is a never-ending task. Hydrazones and quinolines possess a wide variety of biological activities. Herewith, eleven quinoline hydrazone derivatives have been designed, synthesized, characterized and evaluated for their antibacterial activity and antitubercular potential against Mtb WT H37Rv. Compounds QH-02, QH-04 and QH-05 were found to be promising compounds with an MIC value of $4 \mu \mathrm{g} / \mathrm{mL}$ against Mtb WT H37Rv. Compounds QH-02, QH-04, QH-05, and $\mathbf{Q H - 1 1}$ were also found to be active against bacterial strains including Acinetobacter baumanii, Escherichia coli and Staphylococcus aureus. Further, we have carried out experiments to confirm the cytotoxicity of the active compounds and found them to be non-toxic.
\end{abstract}

Keywords: Quinoline, Hydrazone, Antituberculosis, Antibacterial activity, Cytotoxicity

\section{Introduction}

There is an urgent need for the screening of new bioactive molecules with new targets and novel mechanisms of action to address the emerging problem of antibacterial resistance. There are about 558,000 reported cases of rifampicin-resistant tuberculosis. Further, 82\% had multidrug-resistant tuberculosis (MDR-TB), with maximum incidence in India, China and the Russian Federation [1]. Discovery of novel chemical scaffolds with

\footnotetext{
*Corresponding author: Sangeetha Subramanian, SBST, Vellore Institute of Technology, Vellore - 632014, Tamil Nadu, India E-mail: sangeethasubramanian@vit.ac.in; Tel.:+971501099154 Shruthi T G, Sumesh Eswaran, Anthem Biosciences Pvt, Ltd., Bangalore-560099, Karnataka, India
}

novel mechanisms of action are necessary to develop novel therapeutic treatment combinations. Among heterocyclic compounds, compounds with a quinoline core have gained much importance in medicinal chemistry. Quinoline compounds are vital structures in medicinal chemistry due to their wide spectrum of biological activity, including anti-inflammatory [2], anticancer [3,4], antihypertensive [5], tyrokinase PDGF-RTK-inhibiting [6], anti-HIV [7], anti-malarial $[8,9]$ and anti-bacterial activity $[10,11]$. They are also known to exhibit excellent anti-TB $[12,13,14]$ properties. For example, Bedaquiline is an important quinoline-based anti-TB drug for the treatment of MDR-TB [15]. Quinoline is also a key component of many naturallyoccurring bioactive compounds.

Hydrazones belong to a class of organic compounds containing a $\mathrm{C}=\mathrm{N}$ bond, in which the nitrogen atom is nucleophilic and the carbon atom has both electrophilic and nucleophilic character. Owing to their biological and pharmacological properties, combining hydrazones with other heterocyclic compounds leads to diverse biological and pharmacological properties.

Quinoline hybrids combine polar and nonpolar properties, allowing them to permeate bacterial cells. It is evident from the literature that quinoline-based hydrazone scaffolds exhibit excellent antibacterial and anti-TB properties. The quinoline hydrazone derivatives synthesized by Eswaran et al. showed better antituberculosis potency than rifampin and isoniazid [16], while new fluorine-substituted hydrazones also exhibited good anti-tuberculosis potency [17]. These molecules also showed remarkable anti-cancer properties [18]. The quinoline hydrazone moiety has tremendously enhanced the anti-TB activity of these compounds.

We have designed new quinoline derivatives via two synthetic routes. These are the unique scaffolds with quinoline, piperazine or morpholine and hydrazones present in the molecules. The idea to design these two completely different scaffolds was motivated by a survey of the literature. The intermediate 7-chloro-4-(piperazin-1-yl) quinoline (5) is an important building block in medicinal 
chemistry, where it is combined with other active pharmacophores with diverse pharmacological profiles $[19,20,21]$. Some 7-chloro-4-(piperazin-1-yl)quinolinecarrying propionic acid hydrazone derivatives synthesized by Inam et al. were shown to be effective as antiprotozoal agents [22]. Hydrazone derivatives of quinoline and their $\mathrm{Zn}$ (II) complexes, synthesized by Mandewale, M. C. et al., were good antitubercular agents [23] and the 7-chloro-4quinolinylhydrazone derivatives synthesized by Candea et al. exhibited significant activity comparable with that of the first line drugs, ethambutol and rifampicin [24]. This evidence inspired us to design scaffold 1. 4-hydroxy8-trifluoromethyl-quinoline derivatives were synthesized and screened for in vitro anti-TB activity against various strains of Mycobacterium by Thomas et al. [25]. The mode of action of these active compounds involved docking of receptor enoyl-ACP reductase with the newly synthesized candidate ligands. This encouraged us to design scaffold 2. The overall strategy is to attach hydrazones at the second and fourth positions of the quinoline ring and to screen for resulting antimicrobial activity.

In the present work, all new structures were designed on the basis of combinatorial synthesis, keeping structureactivity relationship studies in mind in line with the current trend in drug discovery. All compounds were characterized by NMR spectra as well as mass spectroscopy. Amongst the tested compounds, $\mathbf{Q H - 0 2 ,} \mathbf{Q H - 0 4 ,} \mathbf{Q H - 0 5}$ and $\mathbf{Q H}-\mathbf{- 1 1}$ displayed promising antimicrobial activity.

\section{Experimental}

\section{Chemistry}

All reagents were purchased from Sigma Aldrich. Solvents used were extra dried. Final purifications were carried out using a Quad Biotage Flash purifier (A Dyax Corp. Company). TLC experiments were performed on aluminabacked silica gel 40 F254 plates (Merck, Darmstadt, Germany). The plates were illuminated under UV (254 nm) and $\mathrm{KMnO}_{4}$. All ${ }^{1} \mathrm{H}$ and ${ }^{13} \mathrm{C}$ NMR spectra were recorded on a Bruker AM-300 (300.12 MHz) and AM-400 (400.13 MHz) (Bruker BioSpin Corp., Germany). Molecular weights of unknown compounds were checked by LCMS 6200 series Agilent Technology. The mass spectra of a few were recorded in a 410 Prostar binary PDA detector (Varian Inc., USA). Chemical shifts are reported in ppm (ס) with reference to internal standard TMS. The signals are designated as follows: s, singlet; $d$, doublet; t, triplet; $\mathrm{dd}$, doublet of doublets; $\mathrm{td}$, triplet of doublets; $\mathrm{tt}$, triplet of triplets; m, multiplet; brs, broad singlet. IR spectra were recorded using a Bruker Alpha FTIR spectrometer using a diamond ATR single reflectance module (32 scans).

\section{General procedure for the synthesis of compounds}

\section{Preparation of 2-[(3-chloro-phenylamino)-methylene]- malonic acid diethyl ester (2)}

A suspension of 3-chloro-phenylamine (1) $50 \mathrm{~g}$ (0.391 mol.) in diethyl ethoxymethylenemalonate $119 \mathrm{~mL}$ (0.587 mol.) was heated at $110{ }^{\circ} \mathrm{C}$ for $4 \mathrm{~h}$. The reaction mixture was cooled to room temperature, the solid formed was placed in hexane (10 vol.), stirred for $15 \mathrm{~min}$ and filtered to get compound (2) as a pale yellow solid. The isolated compound was used in the next step without further purification. Yield: $70 \mathrm{~g}(60 \%)$

\section{Preparation of 7-chloro-4-hydroxyquinoline (3)}

A solution of 2-[(3-chloro-phenylamino)-methylene]malonic acid diethyl ester (2) $50 \mathrm{~g}(0.168 \mathrm{~mol}$.) in Dowtherm medium $\left(100 \mathrm{~mL}, 2 \mathrm{vol}\right.$.) was heated at $240{ }^{\circ} \mathrm{C}$ for $4 \mathrm{~h}$. The reaction mixture was cooled to room temperature. Hexane was added and the mixture was stirred for $15 \mathrm{~min}$, after which the solid precipitate was filtered and dried to get compound (3) as an off-white solid. Yield: $15 \mathrm{~g}(49.7 \%)$

${ }^{1} \mathrm{H}-\mathrm{NMR}\left(\mathrm{CDCl}_{3} 400 \mathrm{MHz}\right) \delta(\mathrm{ppm}): 6.05(\mathrm{~d}, 1 \mathrm{H}$, $\mathrm{J}=7.6 \mathrm{~Hz}, \operatorname{ArH}), 7.32(\mathrm{dd}, 1 \mathrm{H}, \mathrm{J}=8.8,2 \mathrm{~Hz}, \operatorname{ArH}), 7.58(\mathrm{~d}, 1 \mathrm{H}$, $\mathrm{J}=2 \mathrm{~Hz}, \mathrm{ArH}), 7.93(\mathrm{t}, 1 \mathrm{H}, \mathrm{J}=7.2 \mathrm{~Hz}, \mathrm{ArH}), 8.07(\mathrm{~d}, 1 \mathrm{H}, \mathrm{J}=8.8$ $\mathrm{Hz}, \mathrm{ArH}), 11.78$ (brs, $1 \mathrm{H},-\mathrm{OH}) .{ }^{13} \mathrm{C}-\mathrm{NMR}$ (DMSO $\left.100 \mathrm{MHz}\right) \delta$ (ppm): 109.76, 117.90, 123.92, 124.81, 127.75, 136.71, 140.48, 141.26, 176.77. IR (KBr) cm ${ }^{-1}: 3065,2944,1608,1559,814$. LC/ MS (ESI-MS) $\mathrm{m} / \mathrm{z}=180(\mathrm{M}+1)$.

\section{Preparation of 4,7-dichloro-quinoline [26] (4)}

A phosphorus oxychloride (10 $\mathrm{mL}, 1 \mathrm{vol}$.) was added to 7-chloro-4-hydroxyquinoline (3) (10 g, $0.055 \mathrm{~mol}$.) in a round bottom flask equipped with a reflux condenser. The mixture was heated to reflux for $6 \mathrm{~h}$, then allowed to cool to room temperature. The solution was concentrated under high vacuum to a thick oil, then dumped over cracked ice. The resulting solution was neutralized with saturated $\mathrm{NaHCO}_{3}$ (aq.), and the solid precipitated was filtered and washed with water. The solid was dried under vacuum and the crude compound was purified by column chromatography over silica gel using eluent $30 \%$ ethyl 
acetate in hexane to afford 4,7-dichloroquinoline as a white solid. Yield: $8 \mathrm{~g}(72.7 \%)$

${ }^{1} \mathrm{H}-\mathrm{NMR}$ (DMSO $\left.400 \mathrm{MHz}\right) \delta(\mathrm{ppm}):$ 7.79-7.82 (m, 2H, $\operatorname{ArH}), 8.18(\mathrm{~d}, 1 \mathrm{H}, \mathrm{J}=2 \mathrm{~Hz}, \operatorname{ArH}), 8.23(\mathrm{~d}, 1 \mathrm{H}, \mathrm{J}=8.8 \mathrm{~Hz}$, ArH), $8.88\left(\mathrm{~d}, 1 \mathrm{H}, \mathrm{J}=4.8 \mathrm{~Hz}\right.$, ArH). ${ }^{13} \mathrm{C}-\mathrm{NMR}$ (DMSO 100 MHz) $\delta$ (ppm): 122.42, 124.62, 126.11, 128.53, 129.02, 135.77, 141.70, 149.18, 152.24. IR (KBr) $\mathrm{cm}^{-1}: 3433,1606,1608,1553$, 1485, 817. LC/MS (ESI-MS) $\mathrm{m} / \mathrm{z}=198(\mathrm{M}+1)$

\section{Preparation of 7-chloro-4-piperazin-1-yl-quinoline [26] (5)}

To a suspension of 4,7-dichloro-quinoline (4) (50 g, 0.252 mol.) in isopropyl alcohol (150 mL, 3 vol.) was added piperazine (65.2 $\mathrm{g}, 0.757 \mathrm{~mol}$.) at ambient temperature. The reaction mixture was stirred under nitrogen at $90^{\circ} \mathrm{C}$ for $16 \mathrm{~h}$. The reaction mass became a clear solution at the beginning and slow precipitation of the solid was observed. The progress of the reaction was monitored by TLC analysis. The reaction mass was cooled to room temperature and diluted with ethyl acetate $(1 \mathrm{~L}$, 20 vol.). The unreacted piperazine was precipitated and removed by filtration. The filtrated solid was washed with ethyl acetate $(500 \mathrm{~mL})$. The filtrate was washed with water (500 $\mathrm{mL} \times 2)$, dried over sodium sulphate and concentrated under reduced pressure to give the desired crude compound. The crude compound was purified by column chromatography using silica gel (60-120), eluent $5 \%$ methanol in dichloromethane to get the desired compound as a pale yellow solid. Yield: $50 \mathrm{~g}(80.0 \%)$

${ }^{1} \mathrm{H}-\mathrm{NMR}$ (DMSO $\left.400 \mathrm{MHz}\right) \delta$ (ppm): 2.94 (brs, 4H, - $\mathrm{CH}_{2}$ ), 3.06 (brs, 4H, - $\mathrm{CH}_{2}$ ), 6.97 (d, 1H, J = 4.8 Hz, ArH), 7.53 (dd, $1 \mathrm{H}, \mathrm{J}=8.8,2.4 \mathrm{~Hz}, \operatorname{ArH}), 7.96(\mathrm{~d}, 1 \mathrm{H}, \mathrm{J}=2 \mathrm{~Hz}, \operatorname{ArH}), 8.00(\mathrm{~d}$, $1 \mathrm{H}, \mathrm{J}=8.8 \mathrm{~Hz}, \mathrm{ArH}), 8.68$ (d, $1 \mathrm{H}, \mathrm{J}=4.8 \mathrm{~Hz}, \mathrm{ArH}) .{ }^{13} \mathrm{C}-\mathrm{NMR}$ (DMSO $100 \mathrm{MHz}) \delta$ (ppm): 45.99, 53.68, 109.67, 121.88, 126.04, 126.53, 128.53, 133.94, 150.15, 152.63, 157.34. IR (KBr) $\mathrm{cm}^{-1}:$ 3254, 2942, 2824, 1567, 865, 822. LC/MS (ESI-MS) $\mathrm{m} / \mathrm{z}=248(\mathrm{M}+1)$

\section{Preparation of 4-hydroxymethyl-benzaldehyde (5b)}

A solution of terephthalaldehyde (5a) (20 g, 0.149 mol.) in a mixture of ethanol $(200 \mathrm{~mL}, 10 \mathrm{vol}$.) and THF $\left(240 \mathrm{~mL}, 12 \mathrm{vol}\right.$.) was cooled to $0 \pm 5^{\circ} \mathrm{C}$. To the above mixture sodium borohydride (2.25 g, $0.059 \mathrm{~mol}$.) was added in two lots with stirring at $0{ }^{\circ} \mathrm{C}$ for $2 \mathrm{~h}$. The reaction progress was monitored by TLC analysis. The reaction mixture was quenched with ice cold water and acidified with
$1.5 \mathrm{~N} \mathrm{HCl}$ (pH 6). It was concentrated to remove organic solvents and the resultant aqueous layer was extracted with ethyl acetate $(100 \mathrm{~mL} \times 2)$. The combined organic layer was dried over sodium sulphate, filtered and concentrated under vacuum to afford a pale yellow solid. Yield: $10 \mathrm{~g}(49.2 \%)$

${ }^{1} \mathrm{H}-\mathrm{NMR}$ (DMSO $\left.400 \mathrm{MHz}\right) \delta(\mathrm{ppm}): 4.60(\mathrm{~d}, 2 \mathrm{H}), 5.76$ (s, 1H, - -OH), $7.53(\mathrm{~d}, 2 \mathrm{H}, \mathrm{J}=8 \mathrm{~Hz}), 7.87(\mathrm{~d}, 2 \mathrm{H}, \mathrm{J}=8 \mathrm{~Hz}), 9.98$ (s, $1 \mathrm{H},-\mathrm{CHO})$

\section{Preparation of 4-chloromethyl-benzaldehyde (5c)}

A solution of 4-(hydroxymethyl) benzaldehyde (5b) (10 g, $0.073 \mathrm{~mol}$.) in toluene (100 mL, $10 \mathrm{vol}$.) was cooled to $0^{\circ} \mathrm{C}$. Thionyl chloride ( $8 \mathrm{~mL}, 0.110 \mathrm{~mol}$.) was added dropwise, followed by 2 drops of DMF. The resultant mixture was stirred at ambient temperature for $16 \mathrm{~h}$ and the progress of the reaction was monitored by TLC analysis. The reaction mixture was quenched with ice cold water and basified with aqueous sodium bicarbonate solution to attain $\mathrm{pH}=8$. The aqueous layer was extracted with ethyl acetate (100 mL x 2). The combined organic layer was dried over sodium sulphate filtered and concentrated under vacuum to afford crude compound. This was purified by column chromatography over silica gel using eluent $20 \%$ ethyl acetate in hexane. Yield: $7 \mathrm{~g}(62 \%)$

${ }^{1} \mathrm{H}-\mathrm{NMR}\left(\mathrm{CDCl}_{3}, 400 \mathrm{MHz}\right) \delta(\mathrm{ppm}): 4.65$ (s, 2H), 7.57 (d, 2H, J = $8 \mathrm{~Hz}$ ), 7.89 (d, 2H, J = $8 \mathrm{~Hz}$ ), 10.03 (s, 1H, -CHO)

\section{Preparation of 4-[4-(7-chloro-quinolin-4-yl)-piperazin-1- ylmethyl]-benzaldehyde (6)}

To a solution of 7-chloro-4-(piperazin-1-yl) quinoline $\mathrm{HCl}$ salt (5) (5 g, $0.017 \mathrm{~mol}$.) in a mixture of acetonitrile $(50 \mathrm{~mL}$, 10 vol.) and DMF (50 mL, 10 vol.) was added triethyl amine (7.2 mL, 3 eq.) followed by 4-chloromethyl-benzaldehyde (3.26 g, $0.21 \mathrm{~mol}$.) at $0{ }^{\circ} \mathrm{C}$. The resultant mixture was stirred at ambient temperature for $30 \mathrm{~h}$. The progress of the reaction was monitored by TLC analysis. The reaction mixture was diluted with ice cold water $(200 \mathrm{~mL})$ with stirring. The white solid precipitated was filtered and dried under high vacuum to afford the desired compound. Yield: $5 \mathrm{~g}(77.6 \%)$

${ }^{1} \mathrm{H}-\mathrm{NMR}$ (DMSO $\left.400 \mathrm{MHz}\right) \delta$ (ppm): 2.68 (brs, 4H), 3.20 (brs, 4H), $3.71(\mathrm{~s}, 2 \mathrm{H}), 7.00(\mathrm{~d}, 1 \mathrm{H}, \mathrm{J}=5.2 \mathrm{~Hz}), 7.55$ (dd, $1 \mathrm{H}$, $\mathrm{J}=8.8,2 \mathrm{~Hz}), 7.60(\mathrm{~d}, 2 \mathrm{H}, \mathrm{J}=8 \mathrm{~Hz}), 7.90(\mathrm{~d}, 2 \mathrm{H}, \mathrm{J}=8 \mathrm{~Hz})$, $7.94(\mathrm{dd}, 2 \mathrm{H}, \mathrm{J}=8,2 \mathrm{~Hz}), 8.70(\mathrm{~d}, 1 \mathrm{H}, \mathrm{J}=5.2 \mathrm{~Hz}), 10.0(\mathrm{~s}, 1 \mathrm{H}$, -CHO). LC/MS (ESI-MS) m/z = $366(\mathrm{M}+1)$ 
General procedure for preparation of $\mathrm{N}-[1-\{4-[4-(7-$ chloro-quinolin-4-yl)-piperazin-1-ylmethyl]-phenyl\}methylidene]-N'-aryl-hydrazine (QH-01 to $\mathrm{QH}-05)$

To a solution of 4-[4-(7-chloro-quinolin-4-yl)-piperazin1-ylmethyl]-benzaldehyde (6) (500 mg, $1.366 \mathrm{mmol}$.) in ethanol ( $5 \mathrm{~mL}, 10 \mathrm{vol}$.) was added hydrazine hydrochloride derivative $(1.933 \mathrm{mmol}$.$) at 0{ }^{\circ} \mathrm{C}$. The resultant mixture was stirred at ambient temperature for $3 \mathrm{~h}$. The reaction progress was checked by TLC analysis. The reaction mixture was diluted with ice cold water $(20 \mathrm{~mL})$, solid precipitated was filtered and dried under high vacuum to afford desired compound.

Preparation of 3-\{N'-[1-\{4-[4-(7-chloro-quinolin-4-yl)piperazin-1-ylmethyl]-phenyl\}-methylidene]-hydrazino\}benzonitrile (QH-01)

This compound was prepared by reacting 4-[4-(7-chloroquinolin-4-yl)-piperazin-1-ylmethyl]-benzaldehyde (500 mg, $1.366 \mathrm{mmol}$.) with 3-cyanophenylhydrazine hydrochloride (327 mg, $1.933 \mathrm{mmol}$.). Yield: $0.3 \mathrm{~g}$ (45.66\%)

${ }^{1} \mathrm{H}-\mathrm{NMR}\left(\mathrm{D}_{2} \mathrm{O} 400 \mathrm{MHz}\right) \delta$ (ppm): 3.33 (brs, 4H, - $\mathrm{CH}_{2}$ ), 3.47 (brs, 4H, $-\mathrm{CH}_{2}$ ), 4.29 (s, 2H, $\left.-\mathrm{CH}_{2}\right), 7.09(\mathrm{~d}, 1 \mathrm{H}, \mathrm{J}=5.2 \mathrm{~Hz}$ ), $7.16(\mathrm{~d}, 1 \mathrm{H}, \mathrm{J}=7.6 \mathrm{~Hz}), 7.31(\mathrm{~d}, 1 \mathrm{H}, \mathrm{J}=1.2 \mathrm{~Hz}), 7.38-7.42(\mathrm{~m}, 2 \mathrm{H}$, ArH), 7.31-7.43 (m, 3H, ArH), 7.76 (d, 2H, J = $8 \mathrm{~Hz}, \mathrm{ArH}), 7.94$ (s, 1H, ArH), 7.99 (s, 1H, ArH), $8.06(\mathrm{~d}, 1 \mathrm{H}, \mathrm{J}=9.2 \mathrm{~Hz}), 8.69$ $(\mathrm{d}, 1 \mathrm{H}, \mathrm{J}=5.2 \mathrm{~Hz})$

${ }^{13} \mathrm{C}-\mathrm{NMR}$ (DMSO, $\left.100 \mathrm{MHz}\right) \delta(\mathrm{ppm}): 48.23,49.99$, 58.38, 107.86, 111.92, 114.37, 116.79, 118.85, 119.23, 121.94, 122.10, 126.17, 127.70, 129.48, 130.40, 131.91, 136.47, 136.77, 137.61, 142.66, 145.64, 145.81, 158.75. LC/MS (ESI-MS) m/z $=481.6(\mathrm{M}+1)$

Preparation of N-[1-\{4-[4-(7-chloro-quinolin-4-yl)piperazin-1-ylmethyl]-phenyl\}-methylidene]-N'-(4fluoro-phenyl)-hydrazine (QH-02)

This compound was prepared by reacting 4-[4-(7-chloroquinolin-4-yl)-piperazin-1-ylmethyl]-benzaldehyde (500 mg, $1.366 \mathrm{mmol}$.) with 4-fluorophenylhydrazine hydrochloride (314 mg, $1.933 \mathrm{mmol}$.). Yield: $0.35 \mathrm{~g}$ (54\%)

${ }^{1} \mathrm{H}$ NMR (DMSO $\left.400 \mathrm{MHz}\right) \delta$ (ppm): 3.84 (brs, 4H, $-\mathrm{CH}_{2}$ ), 4.14 (brs, 4H, $\left.-\mathrm{CH}_{2}\right), 4.42\left(\mathrm{~s}, 2 \mathrm{H},-\mathrm{CH}_{2}\right), 7.08(\mathrm{~s}, 4 \mathrm{H}$, $\operatorname{ArH}), 7.31(\mathrm{~d}, 1 \mathrm{H}, \mathrm{J}=6.4 \mathrm{~Hz}, \operatorname{ArH}), 7.64(\mathrm{~d}, 2 \mathrm{H}, \mathrm{J}=8 \mathrm{~Hz}), 7.74-$ 7.70 (m, 3H, ArH), 7.89 (s, 1H, ArH), 8.1 (dd, 2H, J = 8, 4.4 $\mathrm{Hz}, \mathrm{ArH}), 8.84$ (d, 1H, J = 6.4 Hz, ArH), 10.55 (s, 1H, -NH),

${ }^{13} \mathrm{C}$ NMR (DMSO, $\left.100 \mathrm{MHz}\right) \delta$ (ppm): 48.91, 50.68, 58.97, 109.43, 113.03, 115.64, 120.71, 125.69, 126.19, 126.28, 127.06, 131.53, 134.33, 135.57, 136.65, 141.85, 148.35, 150.99, 154.82, 155.71, 157.14. LC/MS (ESI-MS) $\mathrm{m} / \mathrm{z}=474.5(\mathrm{M}+1)$
Preparation of N-[1-\{4-[4-(7-chloro-quinolin-4-yl)piperazin-1-ylmethyl]-phenyl\}-methylidene]-N'-(4methoxy-phenyl)-hydrazine (QH-03)

This compound was prepared by reacting 4-[4-(7-chloroquinolin-4-yl)-piperazin-1-ylmethyl]-benzaldehyde (500 mg, $1.366 \mathrm{mmol}$.) with 4-methoxyphenylhydrazine hydrochloride (337 mg, $1.933 \mathrm{mmol}$.$) . Yield: 0.3 \mathrm{~g} \mathrm{(45.2 \% )}$

${ }^{1} \mathrm{H} \mathrm{NMR}\left(\mathrm{CD}_{3} \mathrm{OD} 400 \mathrm{MHz}\right) \delta$ (ppm): 3.25 (brs, 4H, $-\mathrm{CH}_{2}$ ), 3.60 (brs, 4H, $-\mathrm{CH}_{2}$ ), $3.75\left(\mathrm{~s}, 3 \mathrm{H},-\mathrm{CH}_{3}\right), 4.13\left(\mathrm{~s}, 2 \mathrm{H},-\mathrm{CH}_{2}\right)$, $6.84(\mathrm{~d}, 2 \mathrm{H}, \mathrm{J}=8.8 \mathrm{~Hz}, \mathrm{ArH}), 7.04$ (d, 2H, J = 8.8 Hz, ArH), $7.12(\mathrm{~d}, 1 \mathrm{H}, \mathrm{J}=5.6 \mathrm{~Hz}, \mathrm{ArH}), 7.48(\mathrm{~d}, 2 \mathrm{H}, \mathrm{J}=8 \mathrm{~Hz}, \mathrm{ArH}), 7.36$ (dd, 1H, J = 9.2, $2 \mathrm{~Hz}, A r H), 7.7$ (d, 2H, J = $8 \mathrm{~Hz}, A r H), 7.75$ (s, 1H, ArH), 7.96 (s, 1H, ArH), 8.13 (d, 1H, J = 8.8 Hz, ArH), $8.65(\mathrm{~d}, 1 \mathrm{H}, \mathrm{J}=5.6 \mathrm{~Hz}, \mathrm{ArH})$

${ }^{13} \mathrm{C}$ NMR (DMSO, $\left.100 \mathrm{MHz}\right) \delta$ (ppm): 48.83, 50.59, 55.26, 58.93, 109.35, 113.09, 114.61, 120.66, 125.39, 126.14, 126.23, 126.97, 129.59, 131.50, 134.36, 136.18, 148.27, 150.92, 152.72, 155.70. LC/MS (ESI-MS) $\mathrm{m} / \mathrm{z}=486.02(\mathrm{M}+1)$

\section{Preparation of N-[1-\{4-[4-(7-chloro-quinolin-4-yl)-} piperazin-1-ylmethyl]-phenyl\}-methylidene]-N'-p-tolylhydrazine (QH-04)

This compound was prepared by reacting 4-[4-(7-chloroquinolin-4-yl)-piperazin-1-ylmethyl]-benzaldehyde (500 mg, $1.366 \mathrm{mmol}$.) with p-tolylhydrazine hydrochloride (306 mg, $1.933 \mathrm{mmol}$.). Yield: $0.36 \mathrm{~g}(56 \%)$

${ }^{1} \mathrm{H}$ NMR ( $\left.\mathrm{CD}_{3} \mathrm{OD} 400 \mathrm{MHz}\right) \delta(\mathrm{ppm}): 2.24\left(\mathrm{~s}, 3 \mathrm{H},-\mathrm{CH}_{3}\right)$, 3.30 (brs, 4H, $\left.-\mathrm{CH}_{2}\right), 3.61$ (brs, 4H, $\left.-\mathrm{CH}_{2}\right), 4.18\left(\mathrm{~s}, 2 \mathrm{H},-\mathrm{CH}_{2}\right)$, $6.98(\mathrm{~d}, 2 \mathrm{H}, \mathrm{J}=8.4 \mathrm{~Hz}, \mathrm{ArH}), 7.03(\mathrm{~d}, 2 \mathrm{H}, \mathrm{J}=8.8 \mathrm{~Hz}, \mathrm{ArH})$, $7.12(\mathrm{~d}, 1 \mathrm{H}, \mathrm{J}=5.6 \mathrm{~Hz}, \mathrm{ArH}), 7.52(\mathrm{~d}, 2 \mathrm{H}, \mathrm{J}=8 \mathrm{~Hz}, \mathrm{ArH}), 7.58$ (dd, $1 \mathrm{H}, \mathrm{J}=8.2,2 \mathrm{~Hz}, \mathrm{ArH}), 7.7(\mathrm{~d}, 2 \mathrm{H}, \mathrm{J}=8 \mathrm{~Hz}, \mathrm{ArH}), 7.75$ (s, 1H, ArH), $7.96(\mathrm{~s}, 1 \mathrm{H}, \mathrm{ArH}), 8.12(\mathrm{~d}, 1 \mathrm{H}, \mathrm{J}=8.8 \mathrm{~Hz}, \mathrm{ArH})$, $8.64(\mathrm{~d}, 1 \mathrm{H}, \mathrm{J}=5.6 \mathrm{~Hz}, \mathrm{ArH})$

${ }^{13} \mathrm{C}$ NMR (DMSO, $\left.100 \mathrm{MHz}\right) \delta$ (ppm): 24.18, 48.41, 50.22, 58.58, 108.62, 112.13, 119.72, 124.36, 125.56, 126.54, 126.85, 127.04, 131.83, 134.72, 135.65, 137.15, 138.97, 143.16, 145.50, 148.50, 157.27. LC/MS (ESI-MS) $\mathrm{m} / \mathrm{z}=470.5(\mathrm{M}+1)$

\section{Preparation of N-[1-\{4-[4-(7-chloro-quinolin-4-yl)- piperazin-1-ylmethyl]-phenyl\}-methylidene]-N'- (4-isopropyl-pheny)-hydrazine (QH-05)}

This compound was prepared by reacting 4-[4-(7-chloroquinolin-4-yl)-piperazin-1-ylmethyl]-benzaldehyde (500 mg, $1.366 \mathrm{mmol}$.) with 4-isopropylphenylhydrazine hydrochloride (360 mg, $1.933 \mathrm{mmol})$. Yield; $0.35 \mathrm{~g}(51.4 \%)$

${ }^{1} \mathrm{H}$ NMR (CD $\left.{ }_{3} \mathrm{OD} 400 \mathrm{MHz}\right) \delta(\mathrm{ppm}): 1.22$ (d, 6H, -CH3), 2.82 (sept, $1 \mathrm{H},-\mathrm{CH}$ ), 3.49 (brs, $4 \mathrm{H},-\mathrm{CH}_{2}$ ), 3.86 (brs, 4H, $-\mathrm{CH}_{2}$ ), 
4.37 (s, 2H, $\left.-\mathrm{CH}_{2}\right), 7.02(\mathrm{~d}, 2 \mathrm{H}, \mathrm{J}=8.4 \mathrm{~Hz}, \mathrm{ArH}), 7.09$ (d, 2H, $\mathrm{J}=8.4 \mathrm{~Hz}, \operatorname{ArH}), 7.23(\mathrm{~d}, 1 \mathrm{H}, \mathrm{J}=6.4 \mathrm{~Hz}, \operatorname{ArH}), 7.57$ (d, 2H, $\mathrm{J}=8 \mathrm{~Hz}, \mathrm{ArH}), 7.75-7.67$ (m, 4H, ArH), 8.00 (s, 1H, ArH), 8.17 $(\mathrm{d}, 1 \mathrm{H}, \mathrm{J}=9.2 \mathrm{~Hz}, \mathrm{ArH}), 8.68(\mathrm{~d}, 1 \mathrm{H}, \mathrm{J}=6.4 \mathrm{~Hz}, \mathrm{ArH})$

${ }^{13} \mathrm{C}$ NMR (DMSO, $\left.100 \mathrm{MHz}\right) \delta$ (ppm): 24.18, 32.67, 48.41, 50.22, 58.58, 108.62, 112.13, 119.12, 124.36, 125.56, 126.54, 126.85, 127.04, 131.83, 134.72, 135.15, 137.15, 138.97, 143.16, 157.27. LC/MS (ESI-MS) $\mathrm{m} / \mathrm{z}=498.08(\mathrm{M}+1)$

\section{Preparation of 2-Methyl-8-trifluoromethyl-quinolin-4-ol (9)}

To a solution of 2-trifluoromethyl aniline (8) (25 g, $0.155 \mathrm{~mol}$.$) and ethyl acetoacetate (25.1 \mathrm{~mL}, 0.201 \mathrm{~mol}$.) was added polyphosphoric acid (125 g, $5 \mathrm{w} / \mathrm{w})$, and the reaction mixture was stirred at $150{ }^{\circ} \mathrm{C}$ for $2 \mathrm{~h}$. The reaction was monitored by TLC. The reaction mixture was slowly poured into ice water $(500 \mathrm{~mL})$ with vigorous stirring. The precipitate solid was filtered, washed with water and dried under high vacuum at $50{ }^{\circ} \mathrm{C}$ to get the desired product as an off-white solid. Yield: $27 \mathrm{~g}(76.6 \%)$

${ }^{1} \mathrm{H}$ NMR $\left(\mathrm{CDCl}_{3}, 400 \mathrm{MHz}\right) \delta$ (ppm): 2.49 (s, 3H, $\left.-\mathrm{CH}_{3}\right)$, 6.37 (s, 1H, ArH), 7.43 (t, 1H, J = 8.0 Hz, ArH), 7.93 (d, 1H, $\mathrm{J}=6.8 \mathrm{~Hz}, \mathrm{ArH}), 8.32$ (brs, 1H, $-\mathrm{OH}), 8.59$ (d, 1H, J = $8.4 \mathrm{~Hz}$, ArH). LC/MS (ESI-MS) m/z = $228.2(\mathrm{M}+1)$

\section{Preparation of 4-Chloro-2-methyl-8-trifluoromethyl- quinoline (10)}

A solution of 2-Methyl-8-trifluoromethyl-quinoline-4-ol (9) ( $26 \mathrm{~g}, 0.114 \mathrm{~mol}$.) in phosphoryl chloride ( $26 \mathrm{~mL}, 1 \mathrm{vol}$.) was stirred at $80^{\circ} \mathrm{C}$ for $2 \mathrm{~h}$. The reaction was monitored by TLC analysis. When the reaction was complete, the reaction mixture was cooled to room temperature. The organic layer was concentrated under high vacuum to remove excess phosphoryl chloride. The resulting brown residue was poured into ice-cold water and basified using $10 \%$ sodium bicarbonate solution. The solid precipitated was filtered, washed with water and dried to afford the desired compound as a pale brown solid. Yield: $20 \mathrm{~g}$ (71.14 \%)

${ }^{1} \mathrm{H} \mathrm{NMR}\left(\mathrm{CDCl}_{3}, 400 \mathrm{MHz}\right) \delta(\mathrm{ppm}): 2.77$ (s, 3H, - $\left.\mathrm{CH}_{3}\right)$, 7.49 (s, 1H, ArH), 7.62 (t, 1H, J = 8.0 Hz, ArH), 8.10 (d, 1H, $\mathrm{J}=7.2 \mathrm{~Hz}, \operatorname{ArH}), 8.40(\mathrm{~d}, 1 \mathrm{H}, \mathrm{J}=8.4 \mathrm{~Hz}, \operatorname{ArH}) . \mathrm{LC} / \mathrm{MS}$ (ESI-MS) $\mathrm{m} / \mathrm{z}=246.5(\mathrm{M}+1)$

\section{Preparation of 2-Methyl-4-morpholin-4-yl-8- trifluoromethyl-quinoline (11)}

To a solution of 4-chloro-2-methyl-8-trifluoro-quinoline (10) (20 g, $0.081 \mathrm{~mol}$.) in isopropyl alcohol (100 mL) was added morpholine (21 mL, $0.244 \mathrm{~mol}$.). This was heated with stirring at $90^{\circ} \mathrm{C}$ for $30 \mathrm{~h}$. The reaction was monitored by TLC analysis. The reaction mixture was cooled to room temperature and concentrated to dryness. The crude compound was diluted with water (200 mL, 10 vol.) and extracted with dichloromethane (100 mL x 2). The combined organic layer was dried over sodium sulphate, filtered and concentrated under reduced pressure at $40-45^{\circ} \mathrm{C}$ to yield the crude product as a brown solid. It was purified by flash chromatography using $80 \%$ ethyl acetate in hexane. Yield: $16 \mathrm{~g}(66.3 \%)$.

${ }^{1} \mathrm{H} \mathrm{NMR}\left(\mathrm{CDCl}_{3}, 400 \mathrm{MHz}\right) \delta(\mathrm{ppm}): 2.74$ (s, 3H, $\left.-\mathrm{CH}_{3}\right)$, 3.19 (t, 4H, - $\mathrm{CH}_{2}$ ), 3.99 (t, 4H, $-\mathrm{CH}_{2}$ ), 6.84 (s, 1H, ArH), 7.46 (t, $1 \mathrm{H}, \mathrm{J}=8.0 \mathrm{~Hz}, \mathrm{ArH}), 7.99(\mathrm{~d}, 1 \mathrm{H}, \mathrm{J}=6.8 \mathrm{~Hz}, \mathrm{ArH}), 8.19$ (d, $1 \mathrm{H}, \mathrm{J}=8.4 \mathrm{~Hz}, \mathrm{ArH})$

${ }^{13} \mathrm{C}$ NMR (DMSO, $\left.100 \mathrm{MHz}\right) \delta$ (ppm): 25.55, 52.28, 66.03, 110.30, 121.75, 123.25, 124.21, 125.23, 127.54, 128.56, 145.14, 156.37, 160.36. LC/MS (ESI-MS) $\mathrm{m} / \mathrm{z}=297.5(\mathrm{M}+1)$

\section{Preparation of 4-Morpholin-4-yl-8-trifluoromethyl- quinoline-2-carbaldehyde (12)}

To a solution of 2-Methyl-4-morpholin-4-yl-8-trifluoromethyl-quinoline (11) (10 g, $0.033 \mathrm{~mol}$.) in 1,4-dioxane (100 vol.) was added selenium dioxide (4.11 g, $0.037 \mathrm{~mol}$.). This was heated with stirring at $90{ }^{\circ} \mathrm{C}$ for $1 \mathrm{~h}$. The reaction was monitored by TLC analysis. The reaction mixture was cooled to room temperature and filtered to remove inorganics. The filtrate was dried over sodium sulphate, filtered and concentrated under reduced pressure at $40-45^{\circ} \mathrm{C}$ to yield the crude product as a brown solid. It was purified by flash chromatography using $60 \%$ ethyl acetate in hexane. Yield: $6 \mathrm{~g}(57.3 \%)$.

${ }^{1} \mathrm{H} \mathrm{NMR}\left(\mathrm{CDCl}_{3}, 400 \mathrm{MHz}\right) \delta(\mathrm{ppm}): 3.29$ (t, 4H, $\left.-\mathrm{CH}_{2}\right)$, $4.02\left(\mathrm{t}, 4 \mathrm{H},-\mathrm{CH}_{2}\right), 7.57(\mathrm{~s}, 1 \mathrm{H}, \mathrm{ArH}), 7.67(\mathrm{t}, 1 \mathrm{H}, \mathrm{J}=8.0 \mathrm{~Hz}$, ArH), 8.12 (d, 1H, J = 4 Hz, ArH), 8.28 (d, 1H, J = 8 Hz), 10.18 (s, 1H, -CHO). LC/MS (ESI-MS) $\mathrm{m} / \mathrm{z}=311.6(\mathrm{M}+1)$

\section{General procedure for preparation of N-[1-\{4-[4-(7- chloro-quinolin-4-yl)-piperazin-1-ylmethyl]-phenyl\}- methylidene]-N'-aryl-hydrazine (QH-06 to QH-11)}

To a solution of 4-morpholin-4-yl-8-trifluoromethylquinoline-2-carbaldehyde (11) (500 mg, $1.611 \mathrm{mmol}$. in ethanol (10 mL, 20 vol.) was added hydrazine hydrochloride derivative (1.933 mol.). This was stirred at ambient temperature for $5 \mathrm{~h}$. The reaction was monitored by TLC analysis. The reaction mixture was diluted with water and stirred for $30 \mathrm{~min}$, and the solid precipitated was filtered to afford the desired compound. 
Preparation of N-[1-(4-morpholin-4-yl-8-trifluoromethylquinolin-2-yl)-methylidene]-N'-phenyl-hydrazine (QH-06)

This compound was prepared by reacting 4-morpholin4-yl-8-trifluoromethyl-quinoline-2-carbaldehyde (500 mg, $1.611 \mathrm{mmol}$.) with phenylhydrazine hydrochloride $(279 \mathrm{mg}$, 1.933 mmol.). Yield: $0.35 \mathrm{~g}(54.26 \%)$

${ }^{1} \mathrm{H}$ NMR (DMSO, $\left.400 \mathrm{MHz}\right) \delta(\mathrm{ppm}): 3.23\left(\mathrm{t}, 4 \mathrm{H},-\mathrm{CH}_{2}\right)$, $3.91\left(\mathrm{t}, 4 \mathrm{H},-\mathrm{CH}_{2}\right), 6.86(\mathrm{t}, 1 \mathrm{H}, \mathrm{J}=7.2 \mathrm{~Hz}, \mathrm{ArH}), 7.18(\mathrm{dd}, 2 \mathrm{H}$, $\mathrm{J}=8.42 \mathrm{~Hz}, \operatorname{ArH}), 7.32-7.28(\mathrm{~m}, 2 \mathrm{H}, \operatorname{ArH}), 7.60$ (t, $1 \mathrm{H}, \mathrm{J}=8 \mathrm{~Hz}$, ArH), 7.64 (s, 1H, ArH), 7.98 (s, 1H, ArH), 8.08 (d, 1H, $\mathrm{J}=6.8 \mathrm{~Hz}, \operatorname{ArH}), 8.29$ (d, 1H, J = 7.6 Hz), 10.93 (s, 1H, -NH).

${ }^{13} \mathrm{C}$ NMR (DMSO, $\left.100 \mathrm{MHz}\right) \delta$ (ppm): 52.21, 66.09, 104.60,112.62, 120.04, 122.99, 123.82, 125.75, 126.13, 127.89, 128.65, 129.26, 136.95, 144.24, 145.49, 156.02, 156.29. LC/MS (ESI-MS) $\mathrm{m} / \mathrm{z}=401.6(\mathrm{M}+1)$

\section{Preparation of $\mathrm{N}$-(2,5-dimethyl-phenyl)-N'-[1-(4- morpholin-4-yl-8-trifluoromethyl-quinolin-2-yl)- methylidene]-hydrazine (QH-07)}

This compound was prepared by reacting 4-morpholin4-yl-8-trifluoromethyl-quinoline-2-carbaldehyde $(500 \mathrm{mg}$, 1.611 mmol.) with 2,5-dimethylphenylhydrazine hydrochloride (333 mg, $1.933 \mathrm{mmol}$.). Yield: $0.36 \mathrm{~g}$ (52.17\%)

${ }^{1} \mathrm{H}$ NMR (DMSO, $\left.400 \mathrm{MHz}\right) \delta$ (ppm): 2.22 (s, 6H), 3.23 (t, 4H, $-\mathrm{CH}_{2}$ ), 3.91 (t, 4H, $-\mathrm{CH}_{2}$ ), $6.92(\mathrm{~s}, 1 \mathrm{H}, \mathrm{J}=7.2 \mathrm{~Hz}, \mathrm{ArH})$, $6.99(\mathrm{~d}, 1 \mathrm{H}, \mathrm{J}=8 \mathrm{~Hz}, \mathrm{ArH}), 7.42$ (d, 1H, J = 8 Hz, ArH), 7.60 (t, $1 \mathrm{H}, \mathrm{J}=8 \mathrm{~Hz}, \mathrm{ArH}), 7.63$ (s, 1H, ArH), 8.08 (d, 1H, ArH), 8.29 (d, 1H, J = 7.6 Hz), 8.30 (s, 1H), 10.08 (s, 1H, -NH).

${ }^{13} \mathrm{C}$ NMR (DMSO, $\left.100 \mathrm{MHz}\right) \delta$ (ppm): 23.71, 34.39, 51.98, 52.99, 109.11, 121.65, 122.95, 124.34, 127.34, 127.89, 128.42, 134.69, 135.79, 138.43, 148.52, 148.98, 149.69, 151.52, 154.58, 156.87, 167.62, 176.23. LC/MS (ESI-MS) $\mathrm{m} / \mathrm{z}=429.6(\mathrm{M}+1)$

\section{Preparation of N-cyclohexyl-N'-[1-(4-morpholin-4-yl-8- trifluoromethyl-quinolin-2-yl)-methylidene]-hydrazine (QH-08)}

This compound was prepared by reacting 4-morpholin4-yl-8-trifluoromethyl-quinoline-2-carbaldehyde (500 mg, 1.611 mmol.) with cyclohexylhydrazine hydrochloride (291 mg, 1.933 mmol.). Yield: 0.35 g (53.5 \%)

${ }^{1} \mathrm{H}$ NMR (DMSO, $\left.400 \mathrm{MHz}\right) \delta$ (ppm): 1.32-1.35 (m, 5H), 1.61-1.64 (m, 1H), 1.75-1.78 (m, 2H) 1.98-2.01 (m, 2H), 3.16 (t, 4H, $\left.-\mathrm{CH}_{2}\right), 3.88\left(\mathrm{t}, 4 \mathrm{H},-\mathrm{CH}_{2}\right), 7.01(\mathrm{~s}, 1 \mathrm{H}, \mathrm{ArH}), 7.10$ (s, 1H, ArH), 7.61 (t, 1H, J = 7.6 Hz, ArH), 8.10 (d, 1H, J = 7.2 $\mathrm{Hz}, \mathrm{ArH}), 8.28$ (d, 1H, J = $8 \mathrm{~Hz}), 12.01$ (s, 1H, -NH).
${ }^{13} \mathrm{C}$ NMR (DMSO, $\left.75 \mathrm{MHz}\right) \delta$ (ppm): 24.47, 25.38, 31.79, 32.49, 52.27, 58.70, 66.05, 104.23, 109.45, 121.62, 123.27, 123.87, 128.27, 128.72, 133.44, 143.94, 154.58, 156.70, 156.99. LC/MS (ESI-MS) m/z = $407.7(\mathrm{M}+1)$

\section{Preparation of N-(4-methoxy-phenyl)-N'-[1-(4-morpholin- 4-yl-8-trifluoromethyl-quinolin-2-yl)-methylidene]- hydrazine (QH-09)}

This compound was prepared by reacting 4-morpholin4-yl-8-trifluoromethyl-quinoline-2-carbaldehyde (500 mg, $1.611 \mathrm{mmol}$.) with 4-methoxyphenylhydrazine hydrochloride (337 mg, $1.933 \mathrm{mmol}$.$) . Yield: 0.4 \mathrm{~g}$ (57.7 \%)

${ }^{1} \mathrm{H}$ NMR (DMSO, 400 MHz) $\delta(\mathrm{ppm}): 3.22\left(\mathrm{t}, 4 \mathrm{H},-\mathrm{CH}_{2}\right) 3.71$ $\left(\mathrm{s}, 3 \mathrm{H},-\mathrm{CH}_{3}\right), 3.91\left(\mathrm{t}, 4 \mathrm{H},-\mathrm{CH}_{2}\right), 6.91(\mathrm{dd}, 2 \mathrm{H}, \mathrm{J}=6.8,2 \mathrm{~Hz}, \mathrm{ArH})$, 7.13 (dd, 2H, J = 6.8, 2 Hz, ArH), 7.58 (t, 1H, J = 7.6 Hz, ArH), 7.62 (s, 1H, ArH), 7.91 (s, 1H), 8.07 (d, 1H, J = 7.6 Hz, ArH), $8.28(\mathrm{~d}, 1 \mathrm{H}, \mathrm{J}=8.4 \mathrm{~Hz}), 10.82(\mathrm{~s}, 1 \mathrm{H},-\mathrm{NH})$

${ }^{13} \mathrm{C}$ NMR (DMSO, $\left.75 \mathrm{MHz}\right) \delta$ (ppm): 52.26, 55.30, 66.06, 104.36, 113.88, 114.21, 114.21, 114.84, 121.89, 122.31, 123.89, 125.93, 129.05, 129.59, 131.83, 137.74, 142.41, 154.04, 157.37. LC/MS (ESI-MS) m/z = $430.43(\mathrm{M}+1)$

\section{Preparation of N-(4-fluoro-phenyl)-N'-[1-(4-morpholin- 4-yl-8-trifluoromethyl-quinolin-2-yl)-methylidene]- hydrazine (QH-10)}

This compound was prepared by reacting 4-morpholin4-yl-8-trifluoromethyl-quinoline-2-carbaldehyde (500 mg, $1.611 \mathrm{mmol}$.) with 4-fluorophenylhydrazine hydrochloride (314 mg, 1.933 mmol.). Yield: $0.3 \mathrm{~g}$ (44.5\%)

${ }^{1} \mathrm{H}$ NMR (DMSO, $\left.400 \mathrm{MHz}\right) \delta$ (ppm): 3.23 (t, 4H, $-\mathrm{CH}_{2}$ ), 3.91 (t, 4H, - $\mathrm{CH}_{2}$ ), 7.2-7.12 (m, 4H, ArH), 7.60 (t, 1H, ArH), 7.62 (s, 1H, ArH), 7.96 (s, 1H), 8.08 (d, 1H, J = 6.8 Hz, ArH), 8.29 (d, 1H, J = 7.6 Hz), 10.93 (s, 1H, -NH).

${ }^{13} \mathrm{C}$ NMR (DMSO, $\left.75 \mathrm{MHz}\right) \delta$ (ppm): 52.26, 66.13, 104.63, 113.69, 115.98, 122.99, 123.87, 125.81, 127.86, 128.69, 136.94, 140.90, 145.49, 155.44, 155.98, 156.32, 157.78. LC/MS (ESIMS) $\mathrm{m} / \mathrm{z}=419.6(\mathrm{M}+1)$

Preparation of N-(4-isopropyl-phenyl)-N'-[1-(4morpholin-4-yl-8-trifluoromethyl-quinolin-2-yl)methylidene]-hydrazine (QH-11)

This compound was prepared by reacting 4-morpholin4-yl-8-trifluoromethyl-quinoline-2-carbaldehyde $(500 \mathrm{mg}$, $1.611 \mathrm{mmol}$.) with 4-isopropylphenylhydrazine hydrochloride (360 mg, $1.933 \mathrm{mmol}$.). Yield: $0.35 \mathrm{~g}$ (49\%) 
${ }^{1} \mathrm{H}$ NMR (DMSO, $\left.400 \mathrm{MHz}\right) \delta(\mathrm{ppm}): 1.19\left(\mathrm{~d}, 6 \mathrm{H},-\mathrm{CH}_{3}\right)$, 2.83 (sept, $1 \mathrm{H},-\mathrm{CH}), 3.23$ (t, 4H, $-\mathrm{CH}_{2}$ ), 3.91 (t, 4H, $-\mathrm{CH}_{2}$ ), 7.11 (d, 2H, J = 8.4 Hz, ArH), 7.17 (d, 2H, J = $8.4 \mathrm{~Hz}, \operatorname{ArH}), 7.59$ (t, $1 \mathrm{H}, \mathrm{J}=8 \mathrm{~Hz}, \mathrm{ArH}), 7.63(\mathrm{~s}, 1 \mathrm{H}), 7.94(\mathrm{~s}, 1 \mathrm{H}, \mathrm{ArH}), 8.08(\mathrm{~d}$, $1 \mathrm{H}, \mathrm{J}=6.8 \mathrm{~Hz}), 8.29(\mathrm{~d}, 1 \mathrm{H}, \mathrm{J}=7.6 \mathrm{~Hz}, \mathrm{ArH}), 10.85(\mathrm{~s}, 1 \mathrm{H},-\mathrm{NH})$.

${ }^{13} \mathrm{C}$ NMR (DMSO, $\left.75 \mathrm{MHz}\right) \delta$ (ppm): 24.04, 32.69, 52.22, 66.10, 104.56, 112.69, 122.95, 122.50, 123.69, 125.89, 126.09, 126.97, 127.81, 128.60, 136.21, 140.14, 142.28, 145.52, 156.18 . LC/MS (ESI-MS) $\mathrm{m} / \mathrm{z}=443.7(\mathrm{M}+1)$

\section{Biological Experiments}

\section{MIC Assay protocol (turbidometric)}

The test compounds were dissolved in DMSO and doublediluted in a 10-concentration dose response (10-DR), and the culture was added at an inoculum of $3-7 \times 10^{5} \mathrm{cfu} / \mathrm{mL}$. The QC included media controls, growth controls and the reference drug inhibitors (Rifampicin). The assay plates were incubated at $37^{\circ} \mathrm{C}$ for 15 days. The growth appeared as turbidity or as a deposit of cells at the bottom of the well. The results were enumerated and a turbidometric reading was noted. The first dilution that showed growth inhibition was recorded as the MIC (Minimum Inhibitory Concentration).

\section{In Vitro Cytotoxicity Study of QH-02, QH-04, QH-05 \& QH-11}

HepG2 cells grown in DMEM supplemented with $10 \%$ fetal bovine serum were trypsinized. The cells were counted, 96 cell culture plates were filled with 12,000 HepG2 cells per well and the cells were allowed to grow for 48 hours in a $\mathrm{CO}_{2}$ incubator at $37{ }^{\circ} \mathrm{C}$ with $5 \% \mathrm{CO}_{2}$. The $20 \mathrm{mM}$ DMSO stocks of $\mathrm{QH}$ compounds and astemizole were used to prepare test solutions, and after 48 hours of plating the HepG2 cells were treated with test/ control items ranging from 100-1.56 $\mu \mathrm{M}$, in 0.2 mL of DMEM with $2 \% \mathrm{FBS}$, and incubated for 24 hours in a $\mathrm{CO}_{2}$ incubator at $37^{\circ} \mathrm{C}$ using $5 \% \mathrm{CO}_{2}$. About $50 \mu \mathrm{L}$ of treatment medium was removed from each well of the plate and $50 \mu \mathrm{L}$ of $1.4 \mathrm{mg} / \mathrm{mL}$ MTT solution was added. The plates were then incubated for 4 hours. After 4 hours, the medium was entirely removed from the wells and $0.2 \mathrm{~mL}$ of DMSO was added to solubilize the formazan crystals formed. The intensity of the color was measured by reading the plate calorimetrically at 570 $\mathrm{nm}$. The blank subtracted OD values of the compoundtreated wells were compared with vehicle-treated wells to calculate the percentage cell growth. The \% cell growth values were plotted against the log of the tested concentration and analyzed using Graph Pad software to determine the $\mathrm{IC}_{50}$ value.

\section{Results and Discussion}

\section{Chemistry}

Eleven new compounds containing a hybrid of substituted quinoline and hydrazone were synthesized according to the synthetic methodologies presented in scheme 1 and scheme 2. In scheme 1, 3-chloro-phenylamine (1) was converted into 2-[(3-chloro-phenylamino)-methylene]malonic acid diethyl ester (2) by reaction with diethyl ethoxymethylenemalonate at $110{ }^{\circ} \mathrm{C}$, and subsequent cyclisation in Dowtherm medium at $240{ }^{\circ} \mathrm{C}$ afforded 7-chloro-4-hydroxyquinoline (3). The chlorination of the intermediate using $\mathrm{POCl}_{3}$ at reflux temperature resulted in 4,7-dichloro-quinoline (4), and condensation of 4,7-dichloro-quinoline and piperazine in IPA at $95{ }^{\circ} \mathrm{C}$ resulted in 7-chloro-4-piperazin-1-yl-quinoline (5) with excellent yield. The common intermediate, 4-[4-(7-chloroquinolin-4-yl)-piperazin-1-ylmethyl]-benzaldehyde (6), was synthesized by coupling of 4-chloromethylbenzaldehyde with 7-Chloro-4-piperazin-1-yl-quinoline. The target compounds, namely quinoline derivatives carrying the hydrazone moiety, viz. QH-01 to QH-05, were synthesized by coupling 4-[4-(7-chloro-quinolin-4-yl)-piperazin-1-ylmethyl]-benzaldehyde (6) with hydrazine hydrochloride molecules in ethanol with good yield. In scheme 2, 2-trifluoromethyl aniline (8) was consequently converted into 2-methyl-8-trifluoromethyl-quinolin-4-ol (9) via cyclisation using the reagents ethyl acetoacetate and polyphosphoric acid at $150{ }^{\circ} \mathrm{C}$. Intermediate (9) was refluxed with $\mathrm{POCl}_{3}$ to synthesis 4-chloro-2-methyl-8-trifluoro-quinoline (10). It was refluxed with morpholine using IPA solvent at $90{ }^{\circ} \mathrm{C}$ to afford 2-methyl-4-morpholin-4-yl-8-trifluoromethyl-quinoline (11). The key aldehyde intermediate, 4-morpholin-4-yl-8-trifluoromethyl-quinoline-2-carbaldehyde (12), was prepared via oxidation using selenium dioxide in 1,4-dioxane at $90{ }^{\circ} \mathrm{C}$. The target compounds, namely quinoline molecules carrying hydrazone moiety, viz. $\mathbf{Q H}-\mathbf{0 6}$ to $\mathbf{Q H - 1 1}$, were synthesized by coupling 4-morpholin-4-yl-8-trifluoromethyl-quinoline-2-carbaldehyde (12) with hydrazine hydrochloride molecules in ethanol. All the newly synthesized compounds were characterized by ${ }^{1} \mathrm{H}$ and ${ }^{13} \mathrm{C}$ NMR and LC-MS studies. 


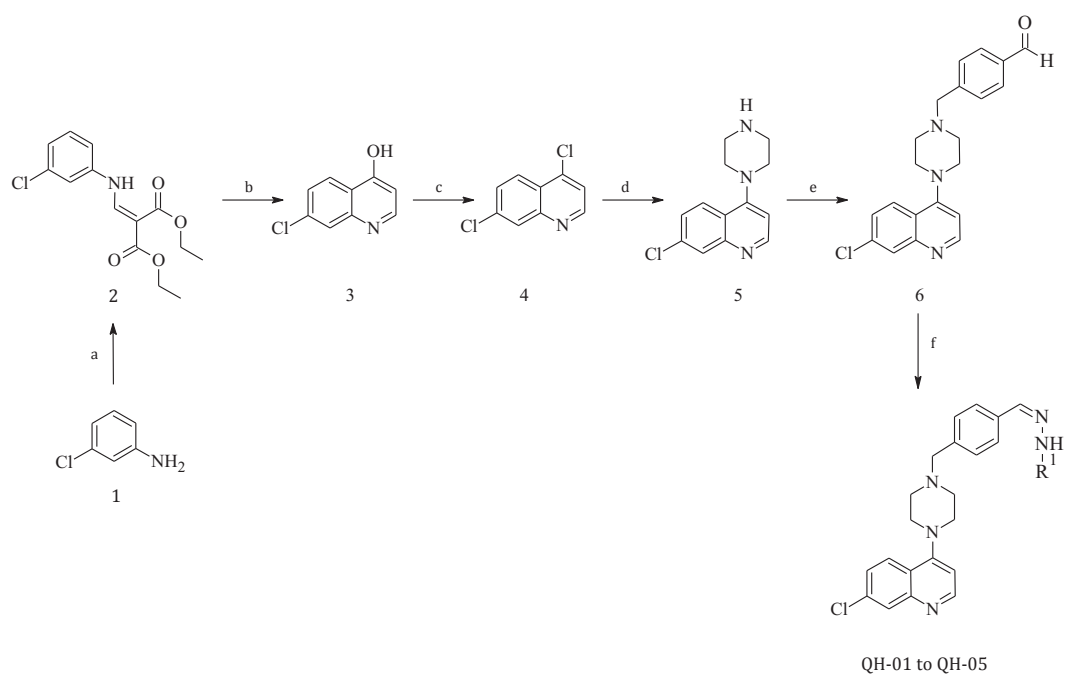

Intermediate 5C:

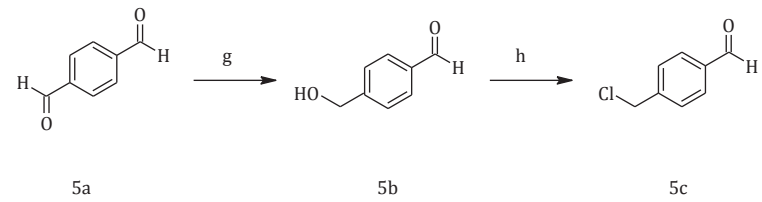

Scheme 1 Synthetic route for quinoline hydrazone derivatives (QH-01 to QH-05).<smiles>Cc1cc(N2CCOCC2)c2ccc(C(F)(F)F)c3c2c1C=CC(C(C)C)=N3</smiles><smiles></smiles>

Scheme 2 Synthetic route of quinoline hydrazone derivatives (QH-06 to QH-11).

Reagents and conditions: (a) diethyl ethoxymethylenemalonate, $110{ }^{\circ} \mathrm{C}$; (b) Dowtherm medium, $240{ }^{\circ} \mathrm{C}$; (c) $\mathrm{POCl}_{3}$, reflux; (d) piperazine, IPA, $95{ }^{\circ} \mathrm{C}$; (e) $\mathrm{Et}_{3} \mathrm{~N}$, ACN, DMF, RT; (f) hydrazine hydrochloride compounds, ethanol, ambient temperature; (g) sodium borohydride, THF, methanol, $0{ }^{\circ} \mathrm{C}$; (h) $\mathrm{SOCl}_{2}$, DMF, RT.

Reagents and conditions: (i) ethyl acetoacetate, polyphosphoric acid $150^{\circ} \mathrm{C}$; (j) $\mathrm{POCl}_{3}$, reflux; (k) morpholine, IPA, $90{ }^{\circ} \mathrm{C}$; (l) selenium dioxide, 1,4 -dioxane, $90{ }^{\circ} \mathrm{C}$; (m) hydrazine hydrochloride molecules, RT.

\section{Biological Investigations}

\section{Antituberculosis studies}

The antitubercular activity of compounds QH-01 to QH-11 was evaluated against Mtb WT H37Rv using the broth microdilution method [27]. A turbidometric assay was employed and the results were counted. Rifampicin (RIF) was used as a standard drug and the first dilution that showed growth inhibition was recorded as the MIC 
(Minimum Inhibitory Concentration). The MIC $(\mu \mathrm{g} / \mathrm{mL})$ values of all compounds against Mtb strain $\mathrm{H} 37 \mathrm{Rv}$ are tabulated in table 1.

Antituberculosis screening data revealed that compounds QH-02, $\mathbf{Q H}-04$ and $\mathbf{Q H}-05$ possessed a moderately promising inhibitory activity of MIC $4 \mu \mathrm{g} / \mathrm{mL}$. This activity is attributed to the presence of the chloro group at position 7 of the quinoline ring and the presence

Table 1 Antitubercular activity of quinoline derivatives carrying hydrazone against Mtb strain H37Rv.

\begin{tabular}{lccc}
\hline Sl.No. & $\begin{array}{c}\text { Compound ID } \\
(\mathrm{QH}-\mathrm{XX})\end{array}$ & $\begin{array}{c}\text { MIC_Mtb } \\
(\mu \mathrm{g} / \mathrm{mL})\end{array}$ & $\begin{array}{c}\text { Cytotoxicity IC } \\
(\mu \mathrm{M})\end{array}$ \\
\hline 1 & $\mathrm{QH}-01$ & 64 & - \\
2 & $\mathrm{QH}-02$ & 4 & $>100$ \\
3 & $\mathrm{QH}-03$ & 16 & - \\
4 & $\mathrm{QH}-04$ & 4 & $>100$ \\
5 & $\mathrm{QH}-05$ & 4 & $>100$ \\
6 & $\mathrm{QH}-06$ & 32 & - \\
7 & $\mathrm{QH}-07$ & 32 & - \\
8 & $\mathrm{QH}-08$ & 32 & - \\
9 & $\mathrm{QH}-09$ & 32 & - \\
10 & $\mathrm{QH}-10$ & 64 & - \\
11 & $\mathrm{QH}-11$ & 16 & - \\
12 & $\mathrm{RIF}$ & 0.025 & $>100$ \\
\hline
\end{tabular}

*Rifampicin (RIF) was used as a control against Mtb strain H37Rv of hydrazones containing 4-flouro phenyl, 4-tolyl and 4-isopropyl phenyl in QH-02, QH-04 and $\mathbf{Q H - 0 5}$ respectively. The hydrazone and quinoline groups are bridged by a piperazine ring in the compound $\mathbf{Q H}-\mathbf{0 1}$ to $\mathbf{Q H}-\mathbf{0 5}$. These new molecules were found to be good starting points to find lead molecules to combat tuberculosis.

\section{Antimicrobial studies}

All compounds (QH-01 to $\mathbf{Q H}-\mathbf{- 1 1}$ ) were tested against Gram Positive and Gram Negative pathogen strains such as Escherichia coli (ATCC 25922), Pseudomonas aeruginosa (ATCC 15442), Enterococcus faecium (ATCC 51559), Staphylococcus aureus (ATCC 33591), Klebsiella pneumonia (ATCC 700603) and Acinetobacter baumanii (ATCC 19606). The assay plates were incubated for 24 hours at $37^{\circ} \mathrm{C}$. At the end of the assay visual turbidometric readings were taken and the results were noted. The MIC $(\mu \mathrm{g} / \mathrm{mL})$ values of all compounds against bacterial strains are tabulated in table 2. Vancomycin and Ciprofloxacin were used as a standard. QH-02 showed promising activity of MIC 4 and $2 \mu \mathrm{g} / \mathrm{mL}$ against Escherichia coli and Staphylococcus aureus strains, respectively. QH-04, QH-05 and QH-11 showed promising activity of MIC $2 \mu \mathrm{g} / \mathrm{mL}$ against Escherichia coliand MIC 4, 2 and $1 \mu \mathrm{g} / \mathrm{mL}$ against Acinetobacter baumaniistains respectively. $\mathbf{Q H - 0 4}$ and $\mathbf{Q H}-\mathbf{1 1}$ showed promising activity of MIC $2 \mu \mathrm{g} / \mathrm{mL}$ against Staphylococcus aureus.

Table 2 Antimicrobial activity of quinoline hydrazone derivatives against bacterial strains.

\begin{tabular}{|c|c|c|c|c|c|c|}
\hline \multirow{2}{*}{$\begin{array}{l}\text { Compound } \\
\text { ID }\end{array}$} & \multicolumn{6}{|c|}{ MIC $(\mu \mathrm{g} / \mathrm{mL})$} \\
\hline & $\begin{array}{c}\text { Escherichia } \\
\text { coli } \\
\text { ATCC } 25922\end{array}$ & $\begin{array}{c}\text { Pseudomons } \\
\text { aeruginosa } \\
\text { ATCC } 15442\end{array}$ & $\begin{array}{c}\text { Enterococcus } \\
\text { faecium } \\
\text { ATCC } 51559\end{array}$ & $\begin{array}{c}\text { Staphylococcus } \\
\text { aureus } \\
\text { ATCC } 33591\end{array}$ & $\begin{array}{c}\text { Klebsiella } \\
\text { pneumoniae } \\
\text { ATCC } 700603\end{array}$ & $\begin{array}{c}\text { Acinetobacter } \\
\text { baumanii } \\
\text { ATCC } 19606\end{array}$ \\
\hline QH-01 & $>32$ & $>32$ & $>32$ & $>32$ & $>32$ & $>32$ \\
\hline $\mathrm{QH}-02$ & 4 & $>32$ & $>32$ & 2 & $>32$ & $>32$ \\
\hline QH-03 & $>32$ & $>32$ & $>32$ & $>32$ & $>32$ & $>32$ \\
\hline QH-04 & 2 & $>32$ & $>32$ & 2 & $>32$ & 4 \\
\hline QH-05 & 2 & $>32$ & $>32$ & $>32$ & $>32$ & 2 \\
\hline QH-06 & $>32$ & $>32$ & $>32$ & $>32$ & $>32$ & $>32$ \\
\hline QH-07 & $>32$ & $>32$ & $>32$ & $>32$ & $>32$ & $>32$ \\
\hline QH-08 & $>32$ & $>32$ & $>32$ & $>32$ & $>32$ & $>32$ \\
\hline QH-09 & $>32$ & $>32$ & $>32$ & $>32$ & $>32$ & $>32$ \\
\hline $\mathrm{QH}-10$ & $>32$ & $>32$ & $>32$ & $>32$ & $>32$ & $>32$ \\
\hline QH-11 & 2 & $>32$ & $>32$ & 2 & $>32$ & 1 \\
\hline Vancomycin & $>16$ & $>16$ & 4 & 0.5 & 0.125 & 0.5 \\
\hline Ciprofloxacin & 0.0312 & 0.25 & 0.5 & 1 & $>16$ & $>16$ \\
\hline
\end{tabular}




\section{Cytotoxicity studies of QH-02, QH-04, QH-05 and QH-11}

We evaluated the cytotoxicity of $\mathbf{Q H}-\mathbf{0 2}, \mathbf{Q H}-\mathbf{0 4}, \mathbf{Q H}-\mathbf{0 5}$ and $\mathbf{Q H}-11$ against the HepG2 cell line by MTT Cytotoxicity assay [28]. After 48 hours of plating, HepG2 cells were treated with test/ control compounds in concentrations ranging from 100-1.56 $\mu \mathrm{M}$. The data obtained in the cytotoxicity studies of quinoline derivatives indicated a high selectivity of these compounds against Mtb. When treated for $24 \mathrm{~h}$, the $\mathrm{IC}_{50}$ values of $\mathbf{Q H}-\mathbf{0 2}, \mathbf{Q H}-\mathbf{0 4}, \mathbf{Q H}-\mathbf{0 5}$ and $\mathbf{Q H}-11$ were found to be $>100 \mu \mathrm{M}\left(\mathrm{IC}_{50}\right.$ values are tabulated in Table 1). Astemizole was used as a control and the $\mathrm{IC}_{50}$ value of astemizole was found to be $7.95 \mu \mathrm{M}$. These four compounds were selected for toxicity study as they possessed the highest potency against Mtb and bacterial strains. Other compounds did not display promising antimicrobial activity and consequently were excluded from the cytotoxicity studies.

\section{Conclusion}

The present research study reports the successful design, synthesis, characterization and antibacterial activity of a new series of quinoline derivatives carrying the hydrazone moiety. The compounds $\mathbf{Q H - 0 2 ,} \mathbf{Q H - 0 4}$ and $\mathbf{Q H}-\mathbf{0 5}$ are a novel class of anti-TB compounds with a moderate MIC value of $4 \mu \mathrm{g} / \mathrm{mL}$. Compound $\mathbf{Q H}-\mathbf{0 2}$ showed promising activities of MIC 4 and $2 \mu \mathrm{g} / \mathrm{mL}$ against Escherichia coli and Staphylococcus aureus strains, respectively. Compounds QH-04, QH-05 and QH-11 showed promising activities of MIC $2 \mu \mathrm{g} / \mathrm{mL}$ against Escherichia coli and MIC 4, 2 and $1 \mu \mathrm{g} / \mathrm{mL}$ respectively against Acinetobacter baumanii strains. QH-04 and QH-11 showed promising activity of MIC $2 \mu \mathrm{g} / \mathrm{mL}$ against Staphylococcus aureus. Cytotoxicity studies confirmed that these active compounds are nontoxic. Being a novel class of compounds, they represent good candidates to extend the work of finding new quinoline hydrazone lead molecules.

Conflicts of Interest: The authors state no conflict of interest.

Acknowledgements: The authors are thankful to the management of Anthem Biosciences, Bangalore, India, for invaluable support and allocation of resources for this work. They are thankful to FNDR, Bangalore, India, for valuable support for this work. They are also thankful to SBST, Vellore Institute of Technology, Tamil Nadu, for valuable support and guidance.

\section{References}

[1] World Health Organization. Global tuberculosis report 2018. Geneva: World Health Organization; 2018.

[2] Berry H, Coquelin JP, Gordon A, Seymour D. Antrafenine, naproxen and placebo in osteoarthritis: a comparative study. Br J Rheumatol. 1983;2(22):89-94.

[3] Wang Y, Ai J, Wang Y, Chen Y, Wang L, Liu G, et al. Synthesis and c-Met kinase inhibition of 3,5-disubstituted and 3,5,7-trisubstituted quinolines: identification of 3-(4-acetylpiperazin-1-yl)-5-(3-nitrobenzylamino)-7- (trifluoromethyl) quinoline as a novel anticancer agent. J Med Chem. 2011;54(7):2127-42.

[4] Mostafa MG, Mansour SA, Mohammed S. Al-D, Marwa G.El-G, Mohammad KP. Design, synthesis and anticancer evaluation of novel quinazoline-aulfonamide hybrids. Molecules. 2016;21(2):189.

[5] Muruganantham N, Sivakumar R, Anbalagan N, Gunasekaran V, Leonard JT. synthesis, anticonvulsant and antihypertensive activities of 8-Substituted quinoline derivatives. Biol Pharm Bull. 2004;27(10):1683-7.

[6] Maguire MP, Sheets KR, McVety K, Spada AP, Zilberstein A. A new series of PDGF receptor tyrosine kinase inhibitors: 3-substituted quinoline derivatives. J Med Chem. 1994;37(14):2129-37.

[7] Strekowski L, Mokrosz JL, Honkan VA, Czarny A, Cegla MT, Patterson SE, et al. Synthesis and quantitative structureactivity relationship analysis of 2-(aryl or heteroaryl) quinolin-4-amines- a new class of anti-HIV-1 agents. J Med Chem. 1991;34(5):1739-46.

[8] Palmer KJ, Holliday SM, Brogden RN. Mefloquine-A review of its antimalarial activity, pharmacokinetic properties and therapeutic efficacy. Drugs. 1993;45(3):430-75.

[9] Kumar A, Srivastava K, Kumar SR, Puri SK, Chauhan PM. Synthesis of new 4-aminoquinolines and quinoline-acridine hybrids as antimalarial agents. Bioorg Med Chem Lett. 2010;20(23):7059-63.

[10] Eswaran S, Adhikari AV, Shetty NS. Synthesis and antimicrobial activities of novel quinoline derivatives carrying 1,2,4-triazole moiety. Eur J Med Chem. 2009;44(11):4637-47.

[11] Nisheeth CD, Bonny YP, Bharti PD. Synthesis and antimicrobial activity of novel quinoline derivatives bearing pyrazoline and pyridine analogues. Med Chem Res. 2017;26(1):109-19.

[12] Lilienkampf A, Mao J, Wan B, Wang Y, Franzblau SG, Kozikowski AP. Structure-activity relationships for a series of quinolinebased compounds active against replicating and nonreplicating Mycobacterium tuberculosis. J Med Chem. 2009;52(7): 2109-18.

[13] Shruthi TG, Eswaran S, Prasad S, Shridhar N, Subramanian S. Synthesis, antituberculosis studies and biological evaluation of new quinoline derivatives carrying 1,2,4-oxadiazole moiety. Bioorg Med Chem Lett. 2019;29(1):97-102.

[14] Jayaprakash S, Iso Y, Wan B, Franzblau SG, Kozikowski AP. Design, synthesis, and SAR studies of mefloquine-based ligands as potential antituberculosis agents. ChemMedChem. 2006;1(6):593-7.

[15] Cox E, Laessig K. FDA Approval of Bedaquiline-The benefitrisk balance for drug-tesistant tuberculosis. N Engl J Med. 2014;371(8):689-91. 
[16] Eswaran S, Adhikari AV, Chowdhury IH, Pal NK, Thomas KD. New quinoline derivatives: synthesis and investigation of antibacterial and antituberculosis properties. Eur J Med Chem. 2010;45(8):3374-83.

[17] Vavrikova E, Polanc S, Kocevar MK, Bosze S, Stolaríkova J. New fluorine-containing hydrazones active against MDR-tuberculosis. Eur J Med Chem. 2011;46(10):4937-45.

[18] Montenegro RC, Lotufo LV, Moraes MO, Pessoa C, Rodrigues FA, Bispo ML. 1-(7-Chloroquinolin-4-yl)-2-[(1H-pyrrol-2-yl) methylene]hydrazine: a potent compound against cancer. Med Chem Res. 2012;21(11):3615-9.

[19] Davis TM, Hung TY, Sim IK, Karunajeewa HA, Ilett KF. Piperaquine: a resurgent antimalarial drug. Drugs. 2005;65(1):75-87.

[20] Kamal A, Shaik A, Shaik AA, Malik MS, Khan IA, Abdullah ST, Ram AB. Quinolylpiperazino substituted thiolactone compounds and process for the preparation thereof. Worldwide patent WO 2011138666A1. 2011 Nov 10.

[21] Jeankumar VU, Reshma RS, Vats R, Janupally R, Saxena S, Yogeeswari $P$, et al. Engineering another class of antitubercular lead: hit to lead optimization of an intriguing class of gyrase ATPase inhibitors. Eur J Med Chem. 2016;122:216-31.

[22] Inam A, Siddiqui SM, Macedo TS, Moreira DR, Leite AC, Soares MB, et al. Design, synthesis and biologicalevaluation of 3-[4-(7-chloro-quinolin-4-yl)-piperazin-1-yl]-propionicacid hydrazones as antiprotozoal agents. Eur J Med Chem. 2014;75:67-76.

[23] Mustapha CM, Bapu TY, Nividc R, Aarti N, Ramesh Y. Synthesis, structural studies and antituberculosis evaluation of new hydrazone derivatives of quinoline and their $\mathrm{Zn}$ (II) complexes. J Saudi Chem Soc. 2016; 22(2):218-228.

[24] Candea AL, Ferreira ML, Pais KC, Cardoso LN, Kaiser CR, Henriques MG, et al. Synthesis and antitubercular activity of 7-chloro-4-quinolinylhydrazones derivatives. Bioorg Med Chem Lett. 2009;19:6272-4.

[25] Thomas KD, Adhikari AV, Telkar S, Chowdhury IH, Mahmood R, Pal NK, et al. Design, synthesis and docking studies of new quinoline-3-carbohydrazide derivatives as antitubercular agents. Eur J Med Chem. 2011;46(11):5283-92.

[26] Fortunak JM, Byrn SR, Dyson B, Ekeocha Z, Ellison T, King CL, et al. An efficient, green chemical synthesis of the malaria drug, piperaquine. Trop J Pharm Res. 2013;12(5):791-8.

[27] Leite CQ, Beretta RZ, Anno IS, Telles MA. Standartization of broth microdilution method for Mycobacterium tuberculosis. Mem Inst Oswaldo Cruz. 2000;95(1):127-129.

[28] Mothanna Al-Q. Rosli R, Swee KY, Abdul RO, Abdul MA, Noorjahan B. Selective Cytotoxicity of Goniothalamin against Hepatoblastoma HepG2 Cells. Molecules. 2011;16(4):2944-59. 